\title{
SELF-EFFICACY AND SALESPERSON JOB INVOLVEMENT AS MEDIATORS OF THE EMOTIONAL INTELLIGENCE - CREATIVITY RELATIONSHIP
}

Felicia G. Lassk, Northeastern University, USA

C. David Shepherd, Georgia Southern University, USA

\begin{abstract}
Creative performance is needed in the sales profession as individual and organizational success depends on supplying innovative and useful solutions for their customers (Chonko and Jones 2005; Lassk and Shepherd forthcoming). Recognizing its important role, creativity is often listed as an essential characteristic of successful salespeople and sales managers (for example, Dubinsky and Ingram 1983; Weitz, Castleberry and Tanner 2009). Emerging research has shown that a leader's emotional intelligence positively supports field members' creative performance (Rego et al. 2007; Zhou and George 2003). Using a sample of 460 field members, this study extends this research by exploring how a field member's perception of their immediate business leader's emotional intelligence impacts his/her creativity and key individual variables, self-efficacy and job involvement.

Structural equation model results found that the relationship between a leader's emotional intelligence is positively related to a field members' creative performance. While it was expected that a partial mediating model would be supported instead a fully mediated model is supported. That is, it appears that when self-efficacy and salesperson job involvement were included in the model, the business leaders' emotional intelligence is reduced in terms of impacting the field's level of creativity. Theoretically, this study confirms Rego et al. (2007). The emotional intelligence - creativity relationship is empirically supported from both the leader and field member perspective. From a managerial perspective, the results of this study suggest that while a leader may create an environment that helps foster creativity, the individual field member's own competencies and involvement are critical to creative performance.
\end{abstract}

References Available Upon Request

The authors would like to acknowledge the financial support of the Direct Selling Education Foundation. 